\title{
NOTE
}

\section{Notes on the geochemistry of native mercury}

\author{
L. H. AHRENS \\ Department of Geochemistry, University of Cape Town, South Africa
}

(Received November 9, 1983: Accepted December 6, 1983)

\begin{abstract}
Attention is drawn to the fact that the first ionization potential (IP) of mercury is conspicuously high, higher than the IPs of any metal. As a consequence, it is suggested that the occurrence of native mercury is due, in part at least, to its very high first ionization potential.
\end{abstract}

Mercury, a Group 2B element, is characteristically chalcophile and occurs either as its own mineral, cinnabar, or is widely dispersed in other sulphide minerals in trace amounts. Secondary features include its occurrence as selenides tellurides, and as amalgams with palladium or silver or gold (BAsu et al., 1981) and occasionally also as native mercury (GoLDSCHмIDT, 1954). The conditions under which mercury can occur in the native state will not be considered here but rather the fact that this extremely rare element can do so. In this respect the behaviour of mercury may be contrasted with its more abundant partners, zinc and cadmium.

Metals which have a characteristic tendency to occur in the native state are gold and some members. of the platinum group; copper and silver exhibit this tendency to a lesser extent. The unique geochemistry of gold has been discussed by this writer (AHRENS, 1953, 1964, 1983). It was pointed out that the remarkable chemical inertness of this element which has a single $\mathrm{s}$ electron outside a closed shell is due to its high ionization potential (IP). It has been pointed out further that all the elements which follow the entry of the $4 \mathrm{f}$ electrons in the build-up (Aufbau) of the elements have elevated ionization potentials relative to their respective Group partners; these metals are $\mathrm{Au}, \mathrm{Hg}, \mathrm{Tl}$, $\mathrm{Pb}, \mathrm{Bi}$ and $\mathrm{Po}$.

When considered as groups in the Periodic
Table of the elements the noble gases, $\mathrm{He}, \mathrm{Ne}$, $\mathrm{Ar}, \mathrm{Kr}$ and $\mathrm{Xe}$, have by far the highest IPs, ranging from $24.6 \mathrm{eV}$ for $\mathrm{He}$ to $12.13 \mathrm{eV}$ for $\mathrm{Xe}$. The outermost electrons of these elements are therefore firmly bound and the noble gases are accordingly the most chemically inert of all the elements; let us now consider mercury.

In the list below, IPs of metals are arranged in order of decreasing IP. The problem, albeit small, arises when attempting to define what precisely is a metal. Conductivity and structure (close packing) are determining factors. Many elements fulfil these requirements satisfactorily but others which are customarily regarded as metals do not. Mercury is one of them and so are $\mathrm{Zn}, \mathrm{Cd}, \mathrm{Ga}, \mathrm{In}, \mathrm{Tl}, \mathrm{Pb}$ and $\mathrm{Bi}$, and although they do not completely fulfil these requirements, they may be regarded as metals. Be has not been included but $\mathrm{Mg}$ has. $\mathrm{Bi}$ and $\mathrm{Sb}$ are also included but not As. The inclusion of Ge is debatable but not Sn.

An arbitrary lower limit has been set in the list which extends as far as the Group 8 element, ruthenium. The limit was purposely set at ruthenium in order to include all Group 8 elements as many of them, notably Pt, Pd, Os and Ir, have high IPs, and their chemical inertness and siderophile tendency will be considered elsewhere.

$\mathrm{Hg}(10.44)>\mathrm{Zn}(9.39)>\mathrm{Au}(9.22)>\operatorname{Ir}(9.1)$

$>\mathrm{Cd}(8.99)>\mathrm{Pt}(8.96)>\mathrm{Os}(8.73)>\mathrm{Pd}(8.33)$ 
$>\mathrm{W}(7.98)>\mathrm{Ta}(7.88)>\mathrm{Re}(7.875)=\mathrm{Co}$ (7.875) $>\mathrm{Fe}(7.87)>\mathrm{Cu}(7.72)>\mathrm{Mg}(7.64)$ $>\mathrm{Ag}(7.57)>\mathrm{Rh}(7.46)>\mathrm{Pb}(7.42)>\mathrm{Ru}$ (7.36).

It is clear that the first ionization potential of mercury is not only greater than those of all the elements listed above, but that this value is quite conspicuously high as the difference between $\mathrm{Hg}\left(\mathrm{I}_{1}\right)$ and $\mathrm{Zn}\left(\mathrm{I}_{1}\right)$ is large.

When attempting to use IPs it would be an oversimplification to assume that IP is the only atomic property which determines whether an element can exist in its native state or not. If this were so, zinc would have a greater tendency than gold to occur in the native state and this is not so. Other atomic properties must clearly be taken into account including possible oxidation states and electronic structure. These properties including IP are all interrelated and it is therefore not easy to decipher which is the single most important property when attempting to unravel a chemical or geochemical problem. However, it must be borne in mind that the first IP of mercury is markedly greater than zinc and all other elements as the diagram (Fig. 1) shows so clearly. It is concluded therefore that the conspicuously high first IP of $\mathrm{Hg}$ is one reason why this extremely rare element can exist in its native state in a geological environment.

\section{REFERENCES}

AHRENS, L. H. (1953) The use of ionization potentials. Part 2. Anion affinity and geochemistry. Geochim. Cosmochim. Acta 3, 1-29.

AHRENS, L. H. (1964) The significance of the chemical bond for controlling the geochemical distribution of the elements. Phys. Chem. Earth 5, 1-54.

AHRENS, L. H. (1983) Ionization potentials - some variations, implications and applications. Pergamon Press, Oxford.

BASU, K., BORTNYKov, N., MOOKHERJEE, A., MOSGOVA, N. and ISEPIN, A. I. (1981) Rare minerals from Rajpura-Dariba, Rajasthan, India II Intermetallic compound $\mathrm{Ag}_{74.2} \mathrm{Au}_{16.4} \mathrm{Hg}_{9.4}$. Neues Jahr. Mineral. Monat, 141, 217-223.

GoldShMIDT, V. M. (1954) Geochemistry. Oxford, at the Clarendon Press.

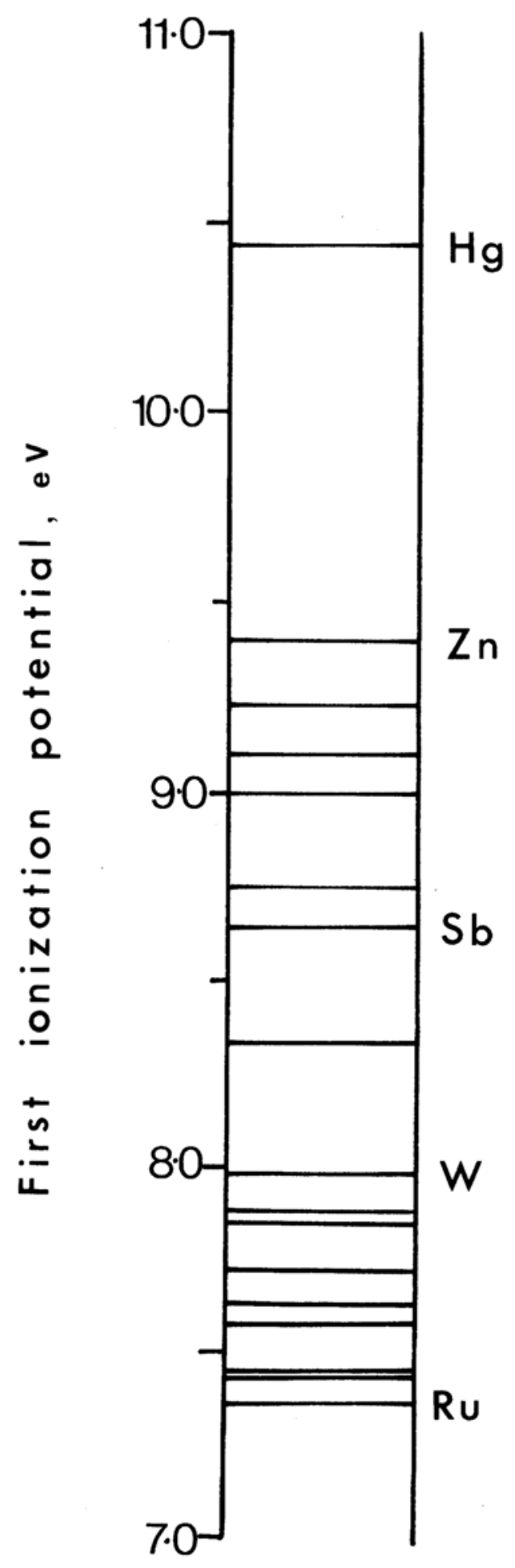

Fig. 1. First ionization potentials (eV) of several metals, arranged in sequence. Note the location of $\mathrm{Hg}$. 